\title{
Salivary Gland Ductal Papilloma
}

National Cancer Institute

\section{Source}

National Cancer Institute. Salivary Gland Ductal Papilloma. NCI Thesaurus. Code C35839.

A benign papillary neoplasm that arises from the salivary glands. This category includes intraductal papilloma, inverted ductal papilloma, and sialadenoma papilliferum. 